Physical Therapy Journal of Indonesia (PTJI) 2021, Volume 2, Number 2: 54-60

E-ISSN : 2722-6034; P-ISSN : 2722-0125

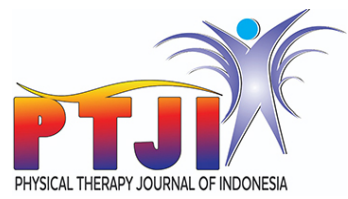

\title{
Comprehensive Physiotherapy Program Improves the Medial Longitudinal Arch of a Male Adolescent with Bilateral Flexible Flat Foot: A Case Report
}

\author{
Sayu Aryantari Putri Thanaya ${ }^{1 *}$, Chika Nabella Jamaluddin ${ }^{2}$
}

\begin{abstract}
Introduction: Flat foot is a common foot deformity marked by the absence of the medial longitudinal arch of the foot. Flexible flat foot is usually symptomless but can affect the biomechanics of the lower extremity and lumbar spine, possibly increasing the risk of pain and injury. Conservative management, including physiotherapy, is important in flat foot management, yet the number of reports regarding physiotherapy for flat foot is scarce. Therefore, this case report aimed to describe a case of bilateral flexible flat foot in a male adolescent who was treated with a comprehensive physiotherapy program.
\end{abstract}

Case Description: A 17-year-old male presented to the physiotherapy clinic with flat foot deformity on both feet. The patient received an hour of comprehensive physiotherapy program per session, twice per week, which included lower extremity stretching, various foot and leg strengthening exercises, proprioception exercises, and an educational aspect. The footprint test was conducted and the patient was evaluated using the Arch Index. The Arch Index measurements according to Cavanagh and Rodgers decreased from 0.38 to 0.32 (left foot) and 0.35 to 0.28 (right foot). Likewise, Staheli's Arch Index measurements also decreased from 1.54 to 1.02 (left foot) and 1.5 to 0.7 (right foot). Conclusion: Following 20 physiotherapy sessions, the patient's Arch Index measurements demonstrated an overall reduction, indicating noteworthy improvements in the medial longitudinal arch height. Hence, it can be concluded that a comprehensive physiotherapy program can help improve the medial longitudinal arch height, and thereby foot posture, of an adolescent with bilateral flexible flat foot.

Keywords: flat foot, foot arch, foot posture, medial longitudinal arch, physiotherapy

Cite this Article: Thanaya, S.A.P.T., Jamaluddin, C.N. 2021. Comprehensive Physiotherapy Program Improves the Medial Longitudinal Arch of a Male Adolescent with Bilateral Flexible Flat Foot: A Case Report. Physical Therapy Journal of Indonesia 2(2): 54-60. D0I: 10.51559/ptji. v2i2.36

'Department of Physiotherapy, Faculty of Medicine, Universitas Udayana, Bali, Indonesia; ${ }^{2}$ TRIDI Medical Center, Batam, Riau Island, Indonesia

\section{*Corresponding to:}

Sayu Aryantari Putri Thanaya;

Department of Physiotherapy,

College of Medicine, Universitas Udayana, Bali, Indonesia, Jalan P. B. Sudirman Denpasar, Bali, Indonesia, 80232;

sayuthanaya@unud.ac.id

Received : 2021-10-14 Accepted : 2021-11-24

Published: 2021-12-02

\section{INTRODUCTION}

Flat foot, also commonly described as pes planus, is a deformity of the foot marked by the collapse or absence of the medial longitudinal arch of the foot. $^{1}$ It is associated with valgus deformity of the hind foot and forefoot abduction. ${ }^{2}$ Flat foot is typically asymptomatic and is normal in children up to 6-7 years old. ${ }^{3}$ The longitudinal arch has a tendency to develop naturally in the first 10 years of life, ${ }^{4-6}$ although some children may not develop a normal arch by adulthood. ${ }^{7}$ In children population, the prevalence of flat foot ranged from $10.3 \%$ to $31.8 \% .^{8-11}$ Previous studies reported a prevalence of $13.6 \%$ in young adults ${ }^{12}$ and $26.6 \%$ in adults aged 40 years and above. ${ }^{13}$

Flat foot and is classified into two general types; flexible flat foot and rigid flat foot. In flexible flat foot, the arch is present during non-weight bearing but disappears during weight bearing, while rigid flat foot is when the arch is absent during both weight bearing and non-weight bearing.,14 Infants and young children are prone to the absence of the medial longitudinal arch due to laxity in the ligaments and lack of neuromuscular control, and most cases of flat foot in children are flexible. ${ }^{7,15}$ It is thought that acquired flat foot deformity occurring in adults may result from dysfunction of any part of the longitudinal arch musculature. The primary factors that are believed to give rise to an acquired flat foot deformity include dysfunction of the posterior tibial tendon, tightness of the triceps surae or isolated gastrocnemius, ligamentous laxity in plantar ligaments, and obesity. ${ }^{7,16}$

Dysfunction of any part of the longitudinal arch musculature, particularly in flexible flat foot, is symptomless in many cases but can affect the biomechanics of the lower extremity and lumbar spine, which may increase the risk of pain and injury. ${ }^{7}$ Flat foot may lead to increased tone and stiffness in lower extremity muscles ${ }^{17}$ as well as fatigue and cramps in lower extremity muscles due to overuse. ${ }^{18}$ Consequently, the appropriate management of flat foot is crucial. Conservative management ought to be sought before surgical intervention, which 
is usually suggested for symptomatic cases that have not responded to conservative management. ${ }^{19}$ Flexible flatfoot often does not need to be treated; nevertheless, conservative treatments may include, corrective shoe wear and/or casting, shoe inserts, orthotic devices and physiotherapy, with particular focus on stretching and strengthening exercises. ${ }^{4,14,19}$

Although flat foot is one of the most common deformity of foot, the number of reports regarding physiotherapy for flat foot is limited. Bent et al. ${ }^{15}$ argues that there is not currently scientific evidence to prove that physiotherapy changes the structure of the flat foot. Several studies have been published but they all looked into the use of foot orthosis or insoles for subjects with flexible flat foot. ${ }^{1,20-22} \mathrm{~A}$ few studies have shown that the medial longitudinal arch can be improved through foot strengthening exercises but the subjects in some of these studies

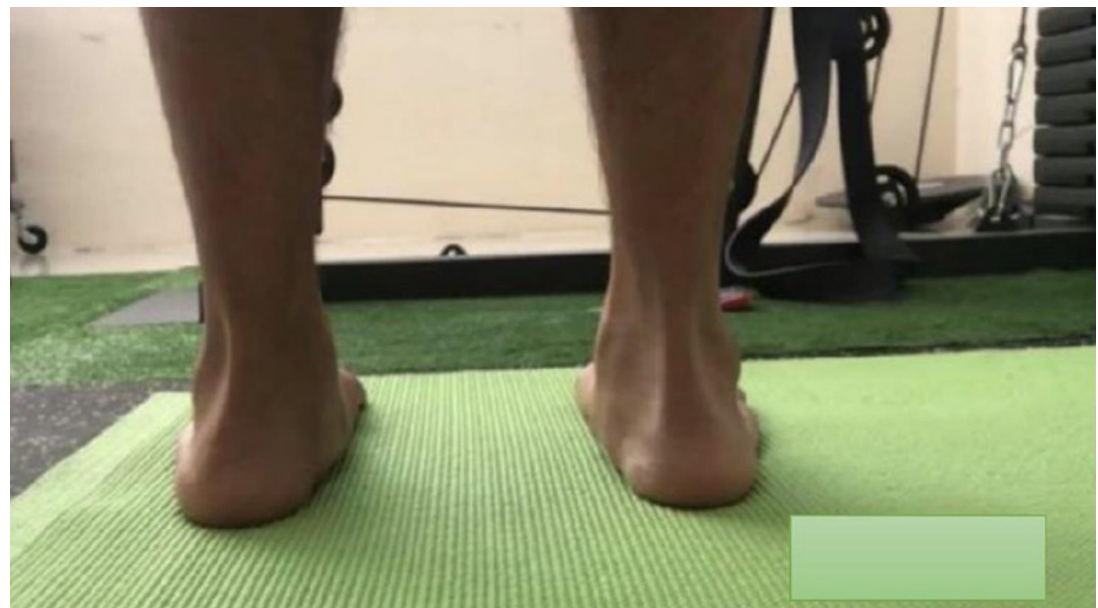

Figure 1. Examination of hindfoot alignment from behind; hindfoot aligned in a valgus position, particularly on the left foot

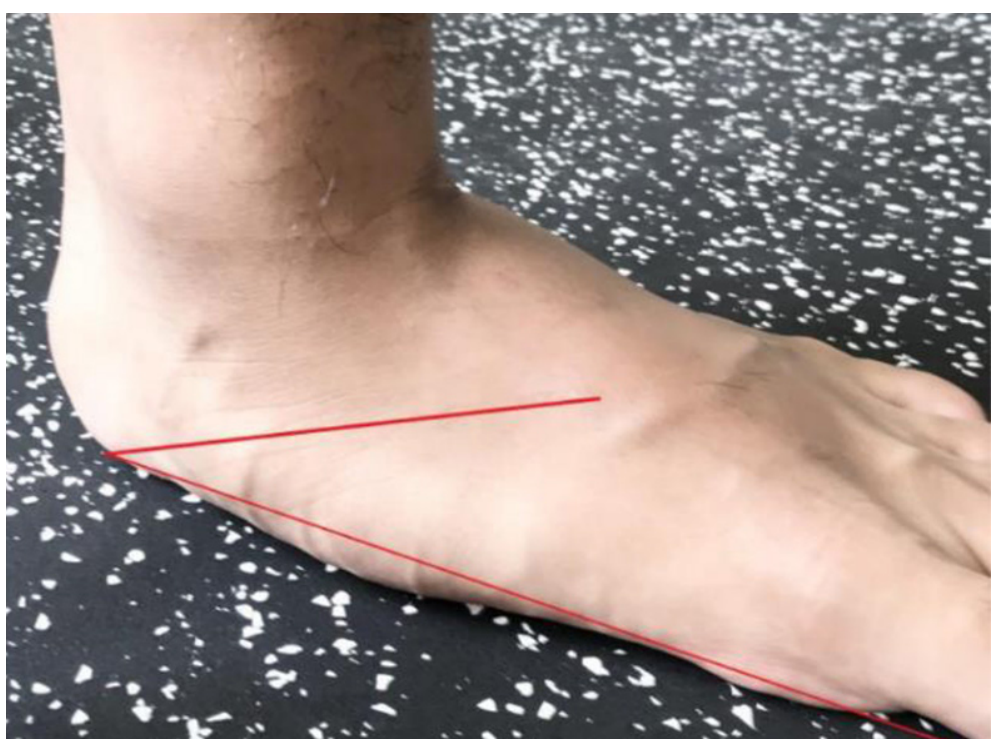

Figure 2. Severe overpronation of left foot were young, healthy adults and subjects with foot problems or injuries were excluded. ${ }^{23-26}$ Moreover, these studies typically evaluated the effects of one or two exercises rather than a comprehensive approach to treatment. One quasi-experimental study was found reporting that stretching and strengthening exercises and trainings for improving the central body stabilization can be effective on improving flat foot deformity, yet this study lacked methodological quality. ${ }^{27}$

Therefore, the number of reports regarding physiotherapy for flat foot is scarce. Given these gaps, the aim of this case report was to describe case of bilateral flexible flat foot in a male adolescent who was treated conservatively with a comprehensive physiotherapy program.

\section{CASE DESCRIPTION}

A 17-year-old male presented to the physiotherapy clinic with flat foot deformity on both feet. His condition was mostly asymptomatic, so the patient had never sought any previous treatment. There was no complaint of pain, no history of trauma or falls, and the patient was otherwise in very good health. The only symptom he frequently experienced was cramping on his calf muscles after running, as he enjoys running and runs regularly for exercise. Initially, he was unaware of having flat feet until he was informed by his coach, who then encouraged him to undergo physiotherapy sessions before taking an anthropometric test as an entrance requirement for the military academy. Although the patient experienced no pain, he wishes to improve his foot posture. The patient had no previous neuromuscular disorders or significant past medical history. There was no family history of a similar deformity or neuromuscular disorder. The patient provided informed consent for the use of data related to this case for publication purposes.

\section{EXAMINATION}

The patient was examined both weight bearing and non-weight bearing. On observation in a seated position, reduced medial longitudinal arch were seen on both feet. In a standing position, the patient was evaluated from behind for hindfoot alignment; as displayed in Figure 1, the hindfoot was aligned in a valgus position, particularly on the left foot, and overpronation were apparent in both ankles. In order to differentiate between flexible or rigid flat foot, the patient was asked to stand on tiptoes; on both feet, the normal contour of the medial longitudinal arch was restored and the hindfoot moved into a varus position, indicating flexible flat feet. 
On physical examination in a standing position, mild overpronation was found on the right feet with mild inside wear, while severe overpronation was found on the left feet with severe inside wear (Figure 2). The patient was able to perform normal inversion and eversion as well as full range of motion (ROM) for plantar flexion and dorsiflexion on both feet. ROM of both knees and hips were normal. Muscle strength was rated 5/5. No swelling or increase in temperature was found at both ankles or foot joints. The footprint test using the simple ink method was conducted on the patient to calculate the plantar Arch Index and further determine the presence of flat foot.

\section{PHYSIOTHERAPY MANAGEMENT}

Physiotherapy management aimed to improve the medial longitudinal arch height and thereby, foot posture. The patient received an hour of physiotherapy program per session twice per week, which included lower extremity stretching,

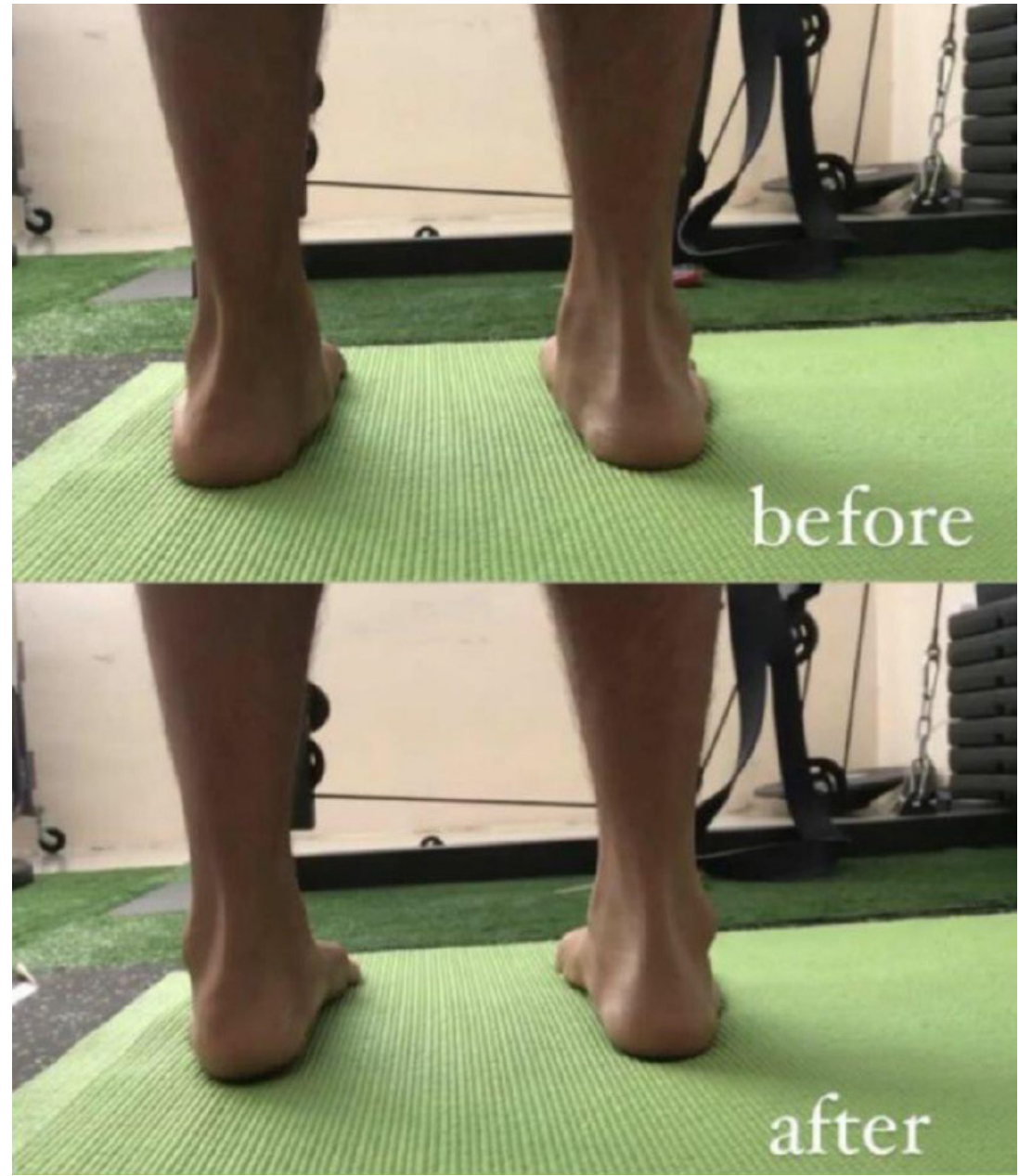

Figure 3. Evaluation of ankle and hindfoot alignment from behind in a standing position; reduced overpronation of the ankles and improved heel alignment can be seen after undergoing physiotherapy various foot and leg strengthening exercises and proprioception exercises, including toe-curling exercises (towel grasping/crunches), short foot exercise, leg extension exercise with a weight of $70 \%$ from 1 RM on every progress, heel raises exercise, single leg squat and weight bearing, and weight shifting exercises with and without BOSU ball. The typical sequence of treatment was stretching first, followed by other exercises. Overall, the patient underwent 20 physiotherapy sessions.

The physiotherapy program also included an educational aspect, in which the patient was educated on how to be more conscious of the way he stood and walked. The patient was taught how to keep his heel in a neutral position while performing the exercises and during standing and walking. He was also taught regarding the foot tripod concept, which is a way to be mindful about how to distribute the weight of the foot evenly when it comes in contact with the ground. The patient was consistently reminded to be mindful of his heel alignment and the foot tripod concept during physiotherapy sessions and while performing daily activities outside of physiotherapy sessions.

\section{EVALUATION/OUTCOMES}

Heel and ankle alignment was evaluated; reduced overpronation of both ankles and improved alignment of the hindfoot can be seen after undergoing physiotherapy, indicating better foot posture (Figure 3).

The footprint test using the simple ink method was conducted and the patient was evaluated using two versions of the Arch Index, which were the Arch Index developed by Cavanagh and Rodgers ${ }^{28}$ and Staheli's Arch Index ${ }^{29}$ (Figures 4 and 5). In general, the Arch Index has been widely used to identify foot type and assess foot structure. The Arch Index defined by Cavanagh and Rodgers ${ }^{28}$ represents the ratio of the middle third of a footprint area relative to the total area without the toes, where a higher ratio indicates a lower arched foot or flatter foot. As shown in Figures 4, the footprint length without the toes $(\mathrm{L})$ is divided into three equal parts. The Arch Index is then calculated by dividing the middle third area of the footprint by the entire footprint area (Arch Index $=\mathrm{B} / \mathrm{A}+\mathrm{B}+\mathrm{C}) .{ }^{30}$ An Arch Index of less than 0.21 , between 0.21 and 0.26 , and greater than 0.26 is considered high arch foot, normal arch foot, and low arch foot, respectively. ${ }^{28}$ This version of the Arch Index has been found to have excellent reliability. ${ }^{30,31}$

On the other hand, Staheli's Arch Index represents the ratio of the central region width of the footprint (A) to the width of the heel region of the 

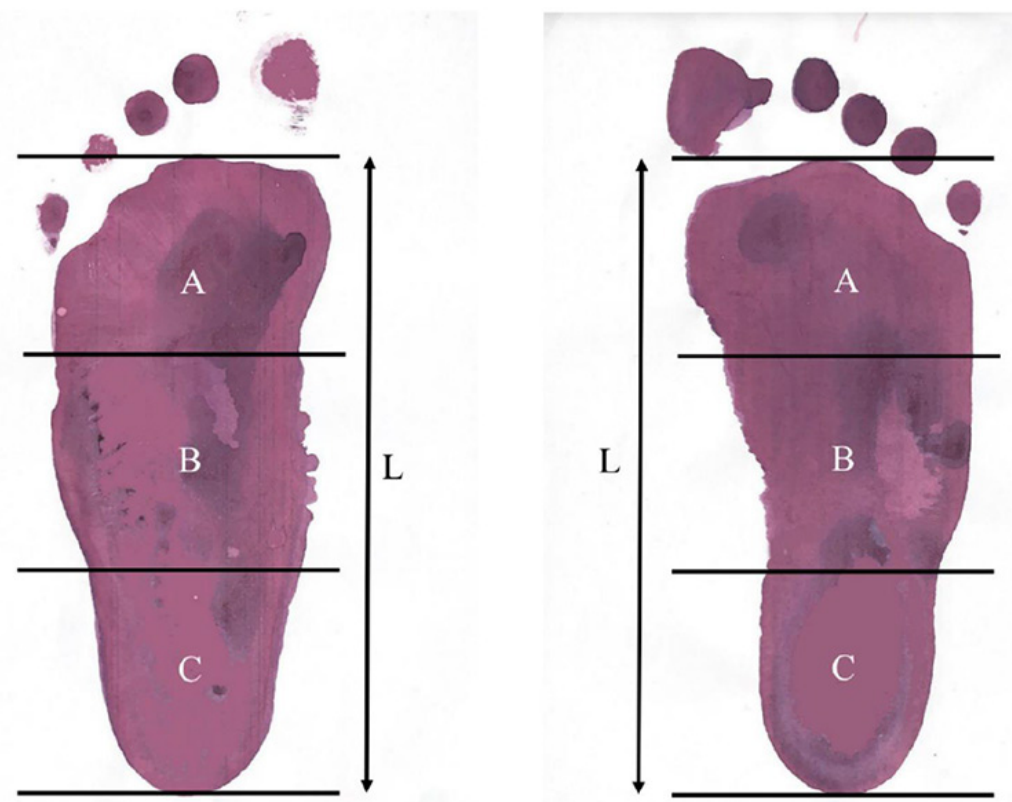

Figure 4. Measurement of Arch Index according to Cavanagh and Rodgers ${ }^{28}$
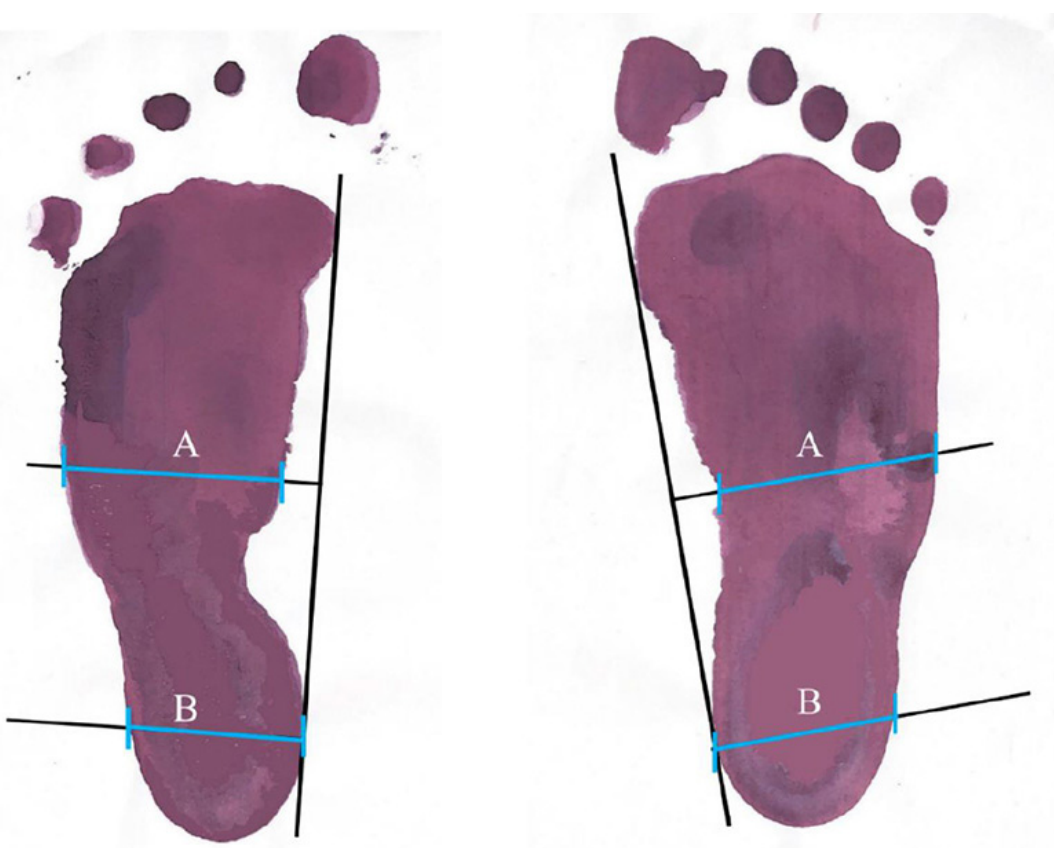

Figure 5. Measurement of Staheli's Arch Index ${ }^{29}$

Table 1. Evaluation of the Arch Index

\begin{tabular}{clccc}
\multirow{2}{*}{ Assessment } & \multicolumn{4}{c}{ Arch index } \\
\cline { 2 - 5 } & \multicolumn{2}{c}{ Cavanagh and Rodgers } & \multicolumn{2}{c}{ Staheli } \\
\cline { 2 - 5 } & Left & Right & 1.54 & Right \\
\hline 1 & 0.38 & 0.35 & 1.21 & 1.09 \\
2 & 0.33 & 0.32 & 1.02 & 0.7 \\
3 & 0.32 & 0.28 & & \\
\hline
\end{tabular}

footprint (B) $\left(\right.$ Arch Index $=$ A/B) $\left(\right.$ Figure 5).$^{32}$ An Arch Index greater than 1.15 should be considered as an indication of flat foot. ${ }^{32}$ Staheli's Arch Index has been found to have excellent reliability, with an intraclass correlation coefficient value $>0.9 .{ }^{31,33,34}$

The results of the patient's Arch Index measurements are summarized in Table 1. In the first assessment, the Arch Indexes according to Cavanagh and Rodgers ${ }^{28}$ in the left foot and right foot were 0.38 and 0.35 , respectively, which decreased to 0.32 and 0.28 , respectively, in the third assessment. Likewise, Staheli's Arch Index also decreased from 1.54 (left foot) and 1.5 (right foot) in the first assessment to 1.02 (left foot) and 0.7 (right foot) the third assessment. Therefore, the results of the Arch Index demonstrated an overall reduction, which indicates that the patient experienced noteworthy improvements in the medial longitudinal arch height in both feet.

\section{DISCUSSION}

The purpose of this present case report was to describe a case of bilateral flexible flat foot in a male adolescent who underwent conservative treatment with physiotherapy, which included a comprehensive program of stretching, strengthening and proprioception exercises, and teaching the patient to be mindful of the way he stood and walked. The findings of our study suggest that a comprehensive physiotherapy program was beneficial in improving the medial longitudinal arch height and thereby foot posture of both feet, shown through improvements in the Arch Index, improved alignment of the hindfoot and reduced overpronation in both ankles.

In cases of flexible flat foot, conservative approach should always be attempted before surgery. ${ }^{19}$ It is commonly agreed that stretching should be included in the conservative management. Accordingly, in the present study, stretching of the gastrocnemius muscle and tendo-achilles complex were given to the patient, aiming to decrease tightness in the achilles tendons and induce varus and adduction of the feet. Some authors believe stretching of the tendo-achilles complex may help counter an equinus deformity. ${ }^{15,19}$

During weight bearing activities, the principal elements that play a role in maintaining the medial longitudinal arch height include bony structure and ligaments that provide passive support, as well as extrinsic and intrinsic foot muscles that provide active support. ${ }^{35-37}$ Extrinsic foot muscles, for example, the posterior tibialis muscle, provide strong support for the medial longitudinal arch; however, it has been revealed that the plantar intrinsic foot muscles of people with flat foot are 
atrophied compared to those with a normal foot arch. ${ }^{38}$ The flexor digitorum brevis, flexor hallucis brevis and abductor hallucis, for example, are intrinsic foot muscles that work at segmental levels to stabilize the medial longitudinal arch during propulsion and prevent excessive pronation during walking. ${ }^{23,35}$ Decreased pronation might lead to increased plantar force on the lateral midfoot, leading to improvement in foot posture. ${ }^{39}$ Hence, strengthening the intrinsic muscles as well as extrinsic foot muscles is an important aspect of treatment for individuals with flat foot.

In the present report, the patient was given toe curling exercises (towel grasping/crunches) and short foot exercise. Toe curling exercises, such as towel grasping/crunches and picking up marbles are commonly given to increase intrinsic foot muscle strength, yet it is argued that these exercises mainly activate or recruit extrinsic foot muscles, such as the flexor digitorum longus, rather than intrinsic foot muscles. ${ }^{23}$ In contrast, short foot exercise is a specific exercise activity that targets the intrinsic muscles of the foot. It aims to activate these inhibited or weakened muscles by increasing or enhancing contact between the foot's sole and the ground $^{40}$ and has been reported to be effective in recruiting the abductor hallucis muscle and prevent excessive reduction of medial longitudinal arch. ${ }^{23,41}$ Various studies have shown short foot exercise to be effective in improving outcomes in subjects with flat foot, including pain, foot posture, plantar pressure and disability. ${ }^{39}$ Okamura et al. ${ }^{42}$ also reported that short-foot exercise can effectively correct static foot position and improve spatiotemporal gait parameters.

In this study, strengthening exercises for the lower leg in the form of single leg weight bearing, leg extension exercise with a weight of $70 \%$ from 1 RM on every progress and heel raises exercise were also provided to the patient. Heel raises are particularly good to strengthen the tibialis posterior muscle, which is said to be one of the muscles commonly suspected of being weak in people with flat foot. ${ }^{43}$ Proprioception exercises were also employed to transfer the body weight towards the exterior part of the foot and improve balance.

The present study also included an education aspect to the program, where the patient was educated to be more conscious of the way he stood and walked. Heel alignment is a crucial aspect of arch building as exercises for flat foot need to be performed while keeping the heel in a neutral position. The patient was taught the foot tripod concept, which is a way to be mindful about how to distribute the weight of the foot evenly when it comes in contact with the ground. ${ }^{43}$ According to
Speck, ${ }^{43}$ foot stability can be obtained through a balance to the 'tripod' points and it is believed that the arches of the foot function optimally when the tripod position is maintained. Before getting into the tripod position, the patient must get into a neutral heel position. Maintaining a foot tripod position while walking may help improve arch stability when walking. However, no empirical studies were found exploring whether the foot tripod concept actually benefits individuals with flat foot or other foot deformities. Most literature on the foot tripod concept are based on expert opinion or the experience of individuals.

In summary, a comprehensive physiotherapy program comprising stretching, strengthening and proprioception exercises, and education on being mindful on how to stand and walk properly appears to be helpful in improving the medial longitudinal arch height and thereby foot posture of a 17-yearold male with bilateral flexible flat foot. Despite the favorable results, it is important to note that this study was a case report involving one patient; hence, the treatment provided may not be suitable for all individuals with flexible flat foot. It is evident that there is a paucity of quality scientific research documenting conservative management with physiotherapy for flexible flat foot.

There are several shortcomings to this current report. We did not include any other outcome measures other than the Arch Index in this study, such as the Foot Posture Index, Foot Function Index, and outcome measures related to balance and gait. Foot posture was evaluated only through observation of heel and ankle alignment after treatment in the fifth session. In addition, the footprint test was conducted only three times throughout the whole encounter with the patient due to time constraints and the inconvenience of using the simple ink method.

\section{CONCLUSION}

It can be concluded that conservative treatment with a comprehensive physiotherapy program can help increase the medial longitudinal arch height and thereby foot posture of an adolescent with bilateral flexible flat foot.

\section{CONFLICT OF INTEREST}

The author declared no potential conflicts of interest.

\section{FUNDING}

The author received no specific funding for this work. 


\section{AUTHOR CONTRIBUTIONS}

SAPT was responsible for the conception of the work, drafting the manuscript and constructing the whole manuscript. CNJ was involved in collecting the case data/information and reviewing the final manuscript.

\section{REFERENCES}

1. Chen Y-C, Lou S-Z, Huang C-Y, Su F-C. Effects of foot orthoses on gait patterns of flat feet patients. Clin Biomech (Bristol, Avon). 2010;25(3):265-70.

2. Klyce W, Lee RJ. Pediatric Problems and Rehabilitation Geared to the Young Athlete. In: Porter DA, Schon LC, editors. Baxter's the Foot and Ankle in Sport. $3^{\text {rd }}$ ed. Philadelphia: Elsevier; 2020. p. 503-15.

3. Brosky JA, Balazsy JE. Functional Anatomy of the Foot and Ankle. In: Placzek JD, Boyce DA, editors. Orthopaedic Physical Therapy Secrets. $3^{\text {rd }}$ ed. St. Louis: Elsevier; 2017. p. 581-6.

4. Yagerman SE, Cross MB, Positano R, Doyle SM. Evaluation and treatment of symptomatic pes planus. Curr Opin Pediatr. 2011;23(1):60-7.

5. Uden H, Scharfbillig R, Causby R. The typically developing paediatric foot: how flat should it be? A systematic review. J Foot Ankle Res. 2017;10(1):37.

6. Edinger J, Sinha A, Fisher M. Congenital and Acquired Disorders. In: Webster JB, Murphy DP, editors. Atlas of Orthoses and Assistive Devices. $5^{\text {th }}$ ed. Philadelphia: Elsevier; 2019. p. 303-312.e3.

7. Raj M, Tafti D, Kiel J. Pes Planus. In: StatPearls [Internet]. Treasure Island (FL): StatPearls Publishing; 2021. Available from: https://www.ncbi.nlm.nih.gov/books/NBK430802/

8. Cetin A, Sevil S, Karaoglu L, Yucekaya B. Prevalence of flat foot among elementary school students, in rural and urban areas and at suburbs in Anatolia. Eur J Orthop Surg Traumatol. 2011;21(5):327-31.

9. Sadeghi-Demneh E, Jafarian F, Melvin JMA, Azadinia F, Shamsi F, Jafarpishe M. Flatfoot in School-Age Children: Prevalence and Associated Factors. Foot Ankle Spec. 2015;8(3):186-93.

10. Pourghasem M, Kamali N, Farsi M, Soltanpour N. Prevalence of flatfoot among school students and its relationship with BMI. Acta Orthop Traumatol Turc. 2016;50(5):554-7.

11. Sadeghi-Demneh E, Melvin JMA, Mickle K. Prevalence of pathological flatfoot in school-age children. Foot. 2018;37:38-44.

12. Aenumulapalli A, Kulkarni MM, Gandotra AR. Prevalence of Flexible Flat Foot in Adults: A Cross-sectional Study. J Clin Diagn Res. 2017;11(6):AC17-20.

13. Pita-Fernandez S, Gonzalez-Martin C, Alonso-Tajes F, Seoane-Pillado T, Pertega-Diaz S, Perez-Garcia S, et al. Flat Foot in a Random Population and its Impact on Quality of Life and Functionality. J Clin Diagn Res. 2017;11(4):LC227.

14. Parvizi J, Kim GK. Flatfoot. In: Parvizi J, Kim GK, editors. High Yield Orthopaedics. Philadelphia: W.B. Saunders; 2010. p. 183-4.

15. Bent MA, Stork NC, Nemeth BA. The diagnosis and management of common childhood orthopedic disorders: An update. Curr Probl Pediatr Adolesc Health Care. 2020;50(10):100884.

16. Van Boerum DH, Sangeorzan BJ. Biomechanics and pathophysiology of flat foot. Foot Ankle Clin. 2003;8(3):419-30.
17. Um G-M, Wang J-S, Park S-E. An analysis on muscle tone of lower limb muscles on flexible flat foot. J Phys Ther Sci. 2015;27(10):3089-92.

18. Lee MS, Vanore J V, Thomas JL, Catanzariti AR, Kogler G, Kravitz SR, et al. Diagnosis and treatment of adult flatfoot. J Foot Ankle Surg. 2005;44(2):78-113.

19. Blitz NM, Stabile RJ, Giorgini RJ, DiDomenico LA. Flexible pediatric and adolescent pes planovalgus: conservative and surgical treatment options. Clin Podiatr Med Surg. 2010;27(1):59-77.

20. Albakr A, Hamad MH, Alwadei AH, Bashiri FA, Hassan $\mathrm{HH}$, Idris $\mathrm{H}$, et al. Idiopathic intracranial hypertension in children: Diagnostic and management approach. Sudan J Paediatr. 2016;16(2):67-76.

21. Saeedi H, Mousavi ME, Majddoleslam B, Rahgozar M, Aminian G, Tabatabai Ghomshe F, et al. The evaluation of modified foot orthosis on muscle activity and kinetic in a subject with flexible flat foot: Single case study. Prosthet Orthot Int. 2013;38(2):160-6.

22. Barati K, Saeedi H, Hajiaghaei B, Jalali M, Curran S. The effect of hydrodynamic insole on foot kinematics in individuals with flexible flatfoot: Case series using a singlesubject design. Proc Inst Mech Eng Part H J Eng Med. 2019;233(4):407-13.

23. Mulligan EP, Cook PG. Effect of plantar intrinsic muscle training on medial longitudinal arch morphology and dynamic function. Man Ther. 2013;18(5):425-30.

24. Kim E-K, Kim JS. The effects of short foot exercises and arch support insoles on improvement in the medial longitudinal arch and dynamic balance of flexible flatfoot patients. J Phys Ther Sci. 2016;28(11):3136-9.

25. Goo Y-M, Kim T-H, Lim J-Y. The effects of gluteus maximus and abductor hallucis strengthening exercises for four weeks on navicular drop and lower extremity muscle activity during gait with flatfoot. J Phys Ther Sci. 2016;28(3):911-5.

26. Sulowska I, Oleksy $\mathrm{E}$, Mika A, Bylina D, Sołtan J. The Influence of Plantar Short Foot Muscle Exercises on Foot Posture and Fundamental Movement Patterns in LongDistance Runners, a Non-Randomized, Non-Blinded Clinical Trial. PLoS One. 2016;11(6):e0157917-e0157917.

27. Khamooshi R, Mohammadi Mohammadieh S, Rahnama NR, Rostami Zalani F. Comparing the Effects of Simultaneous Eight-Week Stretching/Strengthening Trainings with Core Stability Exercises on the Flat Foot Deformity of 9 to 13 Year Old Female Students. 2016;1(4):149-56.

28. Cavanagh PR, Rodgers MM. The arch index: A useful measure from footprints. J Biomech. 1987;20(5):547-51.

29. Engel GM, Staheli LT. The natural history of torsion and other factors influencing gait in childhood. A study of the angle of gait, tibial torsion, knee angle, hip rotation, and development of the arch in normal children. Clin Orthop Relat Res. 1974;(99):12-7.

30. Menz HB, Munteanu SE. Validity of 3 Clinical Techniques for the Measurement of Static Foot Posture in Older People. J Orthop Sport Phys Ther. 2005;35(8):479-86.

31. Queen RM, Mall NA, Hardaker WM, Nunley JA. Describing the Medial Longitudinal Arch Using Footprint Indices and a Clinical Grading System. Foot Ankle Int. 2007;28(4):456-62.

32. Hernandez AJ, Kimura LK, Laraya MHF, Fávaro E. Calculation of Staheli's plantar arch index and prevalence of flat feet: a study with 100 children aged 5-9 years. Acta Ortop Bras. 2007;15:68-71.

33. Papuga MO, Burke JR. The Reliability of the Associate Platinum Digital Foot Scanner in Measuring Previously Developed Footprint Characteristics: A Technical Note. J Manipulative Physiol Ther. 2011;34(2):114-8. 
34. Zuil-Escobar JC, Martínez-Cepa CB, Martín-Urrialde JA, Gómez-Conesa A. Medial Longitudinal Arch: Accuracy, Reliability, and Correlation Between Navicular Drop Test and Footprint Parameters. J Manip Physiol Ther. 2018;41(8):672-9.

35. Jung D-Y, Kim M-H, Koh E-K, Kwon O-Y, Cynn H-S, Lee $\mathrm{W}-\mathrm{H}$. A comparison in the muscle activity of the abductor hallucis and the medial longitudinal arch angle during toe curl and short foot exercises. Phys Ther Sport Off J Assoc Chart Physiother Sport Med. 2011;12(1):30-5.

36. Lee J-H, Cynn H-S, Yoon T-L, Choi S-A, Kang T-W. Differences in the angle of the medial longitudinal arch and muscle activity of the abductor hallucis and tibialis anterior during sitting short-foot exercises between subjects with pes planus and subjects with neutral foot. J Back Musculoskelet Rehabil. 2016;29:809-15.

37. Choi J-H, Cynn H-S, Yi C-H, Yoon T-L, Baik S-M. Effect of Isometric Hip Abduction on Foot and Ankle Muscle Activity and Medial Longitudinal Arch During Short-Foot Exercise in Individuals With Pes Planus. J Sport Rehabil. 2021;30(3):368-74.

38. Angin S, Crofts G, Mickle KJ, Nester CJ. Ultrasound evaluation of foot muscles and plantar fascia in pes planus. Gait Posture. 2014;40(1):48-52.
39. Unver B, Erdem EU, Akbas E. Effects of Short-Foot Exercises on Foot Posture, Pain, Disability, and Plantar Pressure in Pes Planus. J Sport Rehabil. 2020;29(4):436-40.

40. Hubbard T, Newsham KR. Strengthening the Intrinsic Foot Muscles. Athl Ther Today. 2010;15(1):32-5.

41. D. SL, James B, Jay H. Considering the Intrinsic Foot Musculature in Evaluation and Rehabilitation for Lower Extremity Injuries. Athl Train \&amp; Sport Heal Care. 2011;3(1):43-7.

42. Okamura K, Fukuda K, Oki S, Ono T, Tanaka S, Kanai $S$. Effects of plantar intrinsic foot muscle strengthening exercise on static and dynamic foot kinematics: A pilot randomized controlled single-blind trial in individuals with pes planus. Gait Posture. 2020;75:40-5.

43. Speck J. The Foot Tripod [Internet]. 2016 [cited 2021 Sep 15]. Available from: https://www.fixflatfeet.com/foottripod/

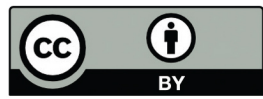

This work is licensed under a Creative Commons Attribution 